\title{
O ESTUDO DIRIGIDO COMO ESTRATÉGIA DE INTEGRAÇÃO DA DIVERSIDADE CULTURAL NO COTIDIANO DA SALA DE AULA
}

\section{DIRECTED STUDY AS AN STRATEGY FOR INTEGRATING CULTURAL DIVERSITY IN DAILY CLASSROOM ACTIVITIES}

\author{
Valner Henrique de Morais ${ }^{1}$ \\ Acir Mário Karwoski ${ }^{2}$
}

\begin{abstract}
Resumo: Ao lidar com a diversidade humana em sala de aula, o diálogo entre o professor e o aluno é importante para se aumentar a bagagem cultural da equipe discente, em uma espécie de avaliação diagnóstica para se conhecer os sujeitos integrantes do processo educativo. Considerando a importância de se analisar as práticas pedagógicas em um processo que envolve ação-reflexão-ação, este artigo tem por objetivo relatar e refletir sobre a relevância de um estudo dirigido dialógico na educação superior, para acolher a diversidade cultural em sala de aula. Para tanto foi realizada uma pesquisa bibliográfica, acompanhada de reflexões sobre experiências colhidas durante atuações do próprio pesquisador no contexto acadêmico. Os resultados apontam que o estudo dialógico pode levantar as diferentes culturas em sala de aula, no momento da mediação dos conhecimentos, relevantes para direcionamento da prática intercultural em que se vincula o cognitivo com a diversidade humana.
\end{abstract}

Palavras-chave: Estudo dirigido. Bagagem cultural. Educação superior.

\begin{abstract}
Working with human diversity in the classroom, the dialogue teacher-pupil is important for enhancing learners' cultural knowledge in a kind of diagnostic evaluation aiming at knowing the educative process' member subjects. Considering the importance of analyzing the pedagogic practices in a process that integrates action-reflection-action, this article aims to report and examine the relevance of a directed study about higher education for welcoming cultural diversity in the classroom. For doing this, a bibliographical survey and the author reflections were carried out concerning this latter own experiences in the academic context. Results show that the dialogic study helps us understand the different cultures in the classroom, in moments of knowledge mediation, which is relevant to guide the intercultural practice in which the cognitive aspect links to human diversity.
\end{abstract}

Key words: Directed stud. Cultural knowledge. Higher education.

\footnotetext{
${ }^{1}$ Graduação em Licenciatura Plena em Química - Universidade de Uberaba, Pós-Graduando, em Docência no Ensino Superior - Universidade Federal do Triangulo Mineiro, prof.morais@yahoo.com.br.

${ }^{2}$ Professor do Curso de Especialização em Docência no Ensino Superior, acirmario@letras.uftm.edu.br
} 


\section{Introdução}

Ao observarmos a diversidade cultural no cotidiano escolar, percebemos a necessidade de elaborar uma estratégia multidisciplinar envolvendo temas de diversas áreas, inclusive reflexões sobre as diferentes culturas que existem em nosso país. Para conhecermos esse universo cultural que há na sala de aula, iniciamos por perceber a identidade de cada aluno, bem como a de seu grupo social, para efetuarmos uma mediação pedagógica intercultural.

É de suma importância observar a diversidade cultural no espaço educativo e sua relação com a escola e a sociedade. Esse é um dos principais papéis da educação: compreender o indivíduo dentro e fora da escola, conhecendo sua cultura, expectativas e prioridades educacionais (FONSECA; MOURA, 2005). Todos os profissionais da educação, em uníssono, devem oferecer aos alunos, subsídios necessários para auxiliá-lo a lidar com as diferenças culturais, sociais, étnicas, entre outras que existem no cotidiano escolar, seja individual ou coletiva.

Para desenvolver uma educação construtiva, voltada para habilidades necessárias à autonomia do ser humano, com identidade social e única, há de se observar diferentes variáveis. Segundo o pensamento de Amaral (2000), essas variáveis podem estar intrínsecas ao ser humano ou ser fruto do contexto, das estratégias de ensino, do tempo e espaço escolar, da bagagem cultural do indivíduo.

Este artigo, fruto de estudos, pesquisas, discussões e também das experiências refletidas dos autores tem, portanto, sua relevância acadêmica, ao conhecermos as ações docentes e a diversidade cultural, uma vez que a complexidade das relações entre escola e diferentes cultura(s) têm mobilizado o nosso interesse durante os últimos anos. Isso com a perspectiva de orientar nossa pesquisa para as práticas pedagógicas concretas, por meio das quais os professores e alunos trabalham esta relação no cotidiano escolar.

Diante desse cenário, este artigo tem por objetivo discutir e refletir sobre as ações voltadas à integração das várias culturas que encontramos no cotidiano da sala de aula, a partir de estudos dirigidos dialógicos, a fim de refletir a postura docente em relação à diversidade cultural em contextos escolares. Além disso, busca conhecer as práticas pedagógicas de professores do Ensino Superior, ao analisar as atividades 
curriculares desenvolvidas na escola e sua relação com as possibilidades do estudo dirigido.

\section{Referencial teórico}

Embora a perspectiva multicultural na dinâmica pedagógica constitua uma abordagem recente em nível internacional, a origem dessa estratégia de ensino em diferentes contextos obedece a origens e motivações específicas, tais como: a tentativa de eliminar o preconceito étnico, a valorização das culturas marginalizadas, o reconhecimento da cultura popular, dentre outras (CUNHA e SOUZA JUNIOR, 2005). Ao valorizar diferentes culturas no espaço universitário, temos como um dos instrumentos possíveis de interação, o estudo dirigido dialogado, oportunizando ao acadêmico apresentar sua bagagem cultural.

Ao abordar o estudo dirigido, Lima (2000) propõe uma estratégia de ensino que pode ser efetivada por meio de fóruns, oficinas, pesquisa de campo, momentos de diálogos com diferentes culturas, por meio da expressão criativa e livre dos acadêmicos em formação. Nessa linha de pensamento, esclarece:

A relação de dialogicidade entre os sujeitos do processo de conhecimento e o discurso pedagógico, permitirá identificar diferentes olhares e diferentes vozes que, no confronto das relações sociais do vivido, produzirão uma grande fertilidade de significados e sentidos da comunicação ao final do processo aula-pesquisa-construção (LIMA, 2000 , p. 153).

$\mathrm{Na}$ realidade, o objetivo de um estudo dialogado é o de buscar contribuições significativas para a constituição de uma didática do ensino em nível superior na qual se procura analisar criticamente a prática de aula universitária com os alunos, por meio da avaliação do processo pedagógico feito com a equipe de discentes no próprio espaço pedagógico e a cada temática desenvolvida. Sendo assim, utiliza-se o espaço universitário na construção de múltipos saberes e de diferentes relações entre o ensino e a pesquisa em sala de aula, aonde o aluno avalia o próprio professor e a si mesmo (aqui incluindo a auto-avaliação). Note que o aluno avalia a postura e a prática do professor, pois muitas vezes o método é que não alcança o objetivo da aprendizagem, momento em que propõe a retomada da temática em uma outra visão metodológica. 
Segundo Dayrell (1996), uma abordagem intercultural representa não somente por razões pedagógicas, mas principalmente por motivos sociais, políticos, ideológicos e culturais. Nesse contexto, a transformação da cultura escolar dominante nos sistemas de ensino se faz urgente, apontando caminhos para incorporar efetivamente a diversidade cultural no cotidiano escolar.

Na Educação Básica, por exemplo, os Parâmetros Curriculares Nacionais (1996), elaborados pelo Ministério de Educação e do Desporto, propõem como um dos temas transversais a pluralidade cultural.

Tratar da diversidade cultural brasileira, reconhecendo-a e valorizando-a e da superação das discriminações aqui existentes é atuar sobre uns dos mecanismos de exclusão, tarefa necessária, ainda que insuficiente, para caminhar na direção de uma sociedade mais democrática. (p.4)

Nesse prisma, a questão das relações entre diversidade cultural e prática docente constitui, portanto, um aspecto relevante na construção de uma escola democrática e plural, que se inicia nos cursos de formação universitária. Entretanto, ao longo desses últimos dez anos pudemos perceber que se trata de uma dimensão raramente trabalhada entre nós educadores, quer seja pela reflexão pedagógica em geral, quer na inclusão efetiva das diferenças culturais no contexto universitário.

De fato, procuramos saber como o acadêmico aprende e constrói seu conhecimento; bem como compreender as dimensões das relações que tal sujeito estabelece no interior do espaço universitário porque é necessário para contextualizar o ensino. Uma abordagem intercultural oferece, atualmente, uma gama de possibilidades de ações, métodos, avaliações e estratégias. Convida-nos a uma prática pedagógica mediadora entre as diferentes culturas existentes no meio universitário, capaz de contribuir com o enriquecimento do fazer pedagógico.

Fleuri (2003, p. 20) afirma que "o interculturalismo expressa uma posição que evidencia a troca e a interação, como forma de potencializar as relações entre os diferentes." Essa abordagem em educação representa uma forma de reconhecer o sentido e a identidade culturais de cada grupo social, mas também reconhece que o conflito pode contribuir para o crescimento cultural coletivo.

Nessa perspectiva, uma prática pedagógica (ação docente) que atue promovendo a "intercultura", busca a relação entre sujeitos e grupos diferentes, 
promovendo a integração das diferentes concepções de mundo, valorizando diferentes visões da sociedade. Podemos dizer: procura-se praticar uma educação que promova e garanta o direito à diversidade, demonstrando o quanto se ganha quando os diferentes se encontram e dialogam.

Sabe-se que o currículo é um campo de polêmica, permeado de ideologia, cultura e relações de poder. Desse modo, o currículo é inseparável da diversidade cultural. Moreira e Silva (1997, p. 78) afirmam que "tanto a teoria educacional tradicional quanto a teoria crítica vêem no currículo uma forma institucionalizada de transmitir a cultura de uma sociedade." Com isso queremos refletir que há também um envolvimento político na escolha e implementação do Currículo escolar, entendido como tudo o que acontece na sala de aula e na escola como um todo. Assim, o Currículo, dentro do processo educacional, está ligado à política cultural, por isso mesmo passível de ser negociado e, portanto, deve ser flexível.

Desse modo, o currículo escolar tem ação direta ou indireta na formação social do aluno. Podemos perceber que a ideologia, cultura e poder nele representado são determinantes da produção do conhecimento no cotidiano escolar. O currículo se refere, pois, a uma realidade histórica, cultural e socialmente construída. Em virtude disso, a proposta curricular se reflete na prática pedagógica, no qual devem conviver lado a lado as diferenças cultuais, reconhecendo-as e valorizando-as.

\section{Estudo dirigido na aula universitária: perspectivas metodológicas}

Os estudos dirigidos, sobretudo os desenvolvidos dentro de uma perspectiva dialógica, portanto interativas, são estratégias valiosas para se conhecer a bagagem cultural de cada aluno. Contribuem para o desenvolvimento de uma reflexão significativa da proposta em relação a uma situação multicultural em sala de aula. Colaboram na compreensão dos acadêmicos ao repensar e utilizar suas próprias bagagens culturais, à medida que o educador os motiva e os ensina a operar os conhecimentos construídos nas oficinas pedagógicas, em situações reais do contexto universitário.

Durante uma aula dialogada, o acadêmico irá se deparar com: diferentes modos de comunicação (verbais e não verbais), imagens e sua representação simbólica, 
números e sua representação matemática e estatística aliada a diferentes modos de conceber o conhecimento (BALZAN, 2000). Isso tudo aliado a um convívio social saudável e harmônico durante o momento do estudo que favorece ao mesmo tempo a inserção social e a construção do conhecimento coletivo.

O perfil do educador ao lidar com essa atividade pedagógica e, mais especificamente, o docente universitário, pressupõe dinamismo, envolvimento, projetos e pesquisas. Isso porque o profissional da educação serve-se de um leque de atuações sugeridas pelos estudos dirigidos, cuja seleção demanda análises e estudos mais fundamentados. Entretanto, antes de empregá-las em sala de aula, o professor universitário tem a tarefa de planejar o tempo escolar estimado, as regras e critérios e uma execução, em uníssono, com as diferenças multiculturais presentes no ambiente acadêmico.

Como toda atuação pedagógica, a utilização de diálogos interculturais como estímulo a aprendizagens, requer a organização e a elaboração de um projeto e a partir desse planejar as atividades, instituindo-se, nessa proposta, as formas de avaliação utilizadas (CASTANHO, 2000). Uma boa estrutura em estudos dirigidos é aquela que contém, dentre outros elementos, objetivos, material, público-alvo definido, método, organização do espaço, o tempo necessário e avaliação dos resultados e respostas.

Prever barreiras, imprevistos e outros entraves, cuja influência possa alterar o rumo da proposta inicial, é um dos procedimentos integrantes da metodologia aplicada na dinâmica. Pois, caso isso aconteça, o profissional necessita ser capaz de nortear o seu trabalho, recriar com segurança novas situações em função do inesperado e tomar decisões na falta de algum elemento que modifique o andamento do processo.

Definir a finalidade ao usar o estudo dirigido no conhecimento da diversidade cultural, é imprescindível. No entanto, ela necessita ser coerente com a habilidade que se procura despertar ou aperfeiçoar em se tratando de fazer pedagógico. Faz parte do processo: rever objetivos, toda vez que for alterar o nível das percepções e abstrações dos acadêmicos; mudar de uma modalidade de atuação para outra no momento oportuno; sugerir uma nova situação não prevista no contexto normal do cotidiano universitário e outras mudanças circunstanciais e ocasionais (LOPES, 2005). Seria muito interessante se o objetivo sugerido voltasse para o contexto universitário e 
trabalhasse as complexidades mais urgentes e necessárias à integração das diversas culturas.

Os recursos e dinâmicas a serem utilizados devem ser cuidadosamente selecionados e inspecionados para evitar alguma inadequação e até mesmo algum conflito desnecessário ou contratempos. Ao material está associado a conveniência pedagógica, por isso cabe diretamente ao profissional estabelecer qual a finalidade, conteúdos, concepções pedagógicas, e outras características materiais.

Devemos estar atentos, pois alguns acadêmicos gostam de extrapolar e polemizar com determinadas temáticas, sendo que nisso pode residir uma característica positiva, por um lado e, por outro lado, desencadear uma situação negativa ou de confrontos no contexto universitário.

O público-alvo, ou seja, os indivíduos envolvidos no estudo intercultural, seu perfil e características, devem ser conhecidos pelos profissionais e entre si, antes de iniciar qualquer atuação para não comprometer o curso e propostas preestabelecidas (MOREIRA, 1997). Nesse sentido, devemos desenvolver dinâmicas com a intenção de estimular o convívio coletivo e cooperativo, respeitando a individualidade, o estilo e a história social de cada acadêmico.

Ao dialogar com a equipe estamos proporcionando, além do crescimento cognitivo do indivíduo, uma oportunidade para experienciar reações emocionais novas e educativas. Embora muitas vezes, advindos de diferentes cursos de uma mesma instituição de ensino superior, na realidade os acadêmicos devem, nesses estudos, se relacionar uns com os outros, sob auxílio de um profissional responsável pela construção de relações pessoais saudáveis (PIMENTA, 2005).

Outra característica a ser observada é a motivação e o interesse pela atividade. Muitos acadêmicos se empolgam no inicio e posteriormente se entregam a uma quase completa letargia. Sempre no final de cada encontro, devemos solicitar a opinião do aluno sobre a avaliação do processo como um todo, sua avaliação sobre as dinâmicas utilizadas e a sugestões possíveis para melhorar o intercâmbio cultural (BALZAN, 2000). Explique-se, contudo, a necessidade de trabalhar melhor o tempo para se elaborar dinâmicas segundo as sugestões propostas a fim de adequar aos estudos dirigidos já iniciados. 
Os procedimentos utilizados durante a dinâmica devem apresentar seqüências lógicas, qualidade na proposição de questionamentos ou problemas e coerência com a real necessidade do acadêmico naquele momento. Estabelecer regras e modos de condução das dinâmicas é uma etapa necessária para compor um conjunto de ações e instruções de caráter funcional e avaliativo, vinculadas à metodologia a ser utilizada no desenvolvimento do estudo (LIMA, 2000). No entanto, é necessário dar vazão à criatividade e extrair desses procedimentos as possiveis situações com as quais iremos enriquecer o processo na coleta da bagagem cultural, orientação e construção de novos saberes. Nesse contexto, aproveitar as situações inesperadas e colher seus significados e suas representações para melhorar o processo pedagógico e enriquecer as práticas educacionais por meio das experiências que advém do inusitado.

Nos procedimentos, deve vir estabelecida a seqüência de todo o processo, cuja permanência seja garantida, através de atividades motivadoras e criativas, envolvendo o acadêmico nas decisões a serem tomadas. Essa é a concepção de trabalho de vários profissionais atuantes na área. Elaborar alterações para simplificar as instruções verbais ou não verbais ou propor, durante a sua realização, novos caminhos a serem seguidos, ao encontro das expectativas dos universitários, caso o instante requerer ou não uma atuação diferente das adotadas.

A organização do espaço e a noção do tempo a ser empregado devem ser previstos com antecedência para manter o fluir e a qualidade da interação durante o estudo dirigido. Escolha espaços mais amplos e arejados, sem muitos detalhes de arquitetura interior, cores claras e decoração com motivos apontados para uma oportunidade de aprendizagem intercultural (CANDAU, 1998). Uma oficina multidisciplinar, na qual os profissionais trabalhem com vários contextos, temas e habilidades específicas, em equipe e prepare o ambiente de forma a integrar os acadêmicos em uma atmosfera propícia, é primordial. Esses e outros cuidados são importantes, a fim de promover uma aprendizagem significativa, apontada para a integração das diversas culturas nos diferentes espaços universitários.

Utilizar o tempo de forma qualitativa, e não apenas matematicamente cronometrado, é uma dimensão do fazer pedagógico a ser trabalhada e explorada enquanto os acadêmicos estiverem expressando suas particularidades cultuais. No contexto dos estudos dirigidos, é importante programá-los condizentes com o tempo disponível, inserindo ai o período compreendido entre uma atividade e outra. Não surte 
efeito e nem motiva o acadêmico, caso o docente queira apresentar uma proposta para discussão no final do tempo, faltando alguns minutos do término da "sessão" (CASTANHO, 2000). Essa situação pode causar expectativa e ao e mesmo tempo ansiedade ao desejarem colocar suas diferentes opiniões.

Ao analisar todos esses elementos, percebe-se que o estudo dirigido é uma seqüência lógica de métodos e técnicas de avaliação pedagógica e orientação aos estudos superiores. Podem conter aprendizagens por meio de variações temáticas para melhor envolver o universitário em outros conteúdos, que não só a ciência ou a pesquisa, mas, enfim, a história, a filosofia, as artes e as dimensões humanas e sociais.

Diante do exposto, passamos a uma análise dos principais componentes que integram um estudo dirigido por meio da interação cultural cuja simbologia, representação e atividades motivem o sucesso diante dos problemas de diferentes abordagens culturais do ensino acadêmico.

A avaliação é processual e dialógica (ROMÃO, 2005), pois não avalia-se o conteúdo, e sim a postura do professor, a postura do aluno frente os conhecimentos mediados e debatidos, durante todo o desenvolvimento do estudo dirigido. Para tanto basta acompanhar os processos acima indicados para que se possa perceber que a avaliação é formativa, forma-se no interior de todo o processo. Não há exames, provas, argüição oral, uma vez que há produção avaliativa, preferencialmente um relato/relatório em que o aluno apresenta o que aprendeu e o que deve ser mantido e/ ou melhorado no processo pedagógico.

\section{Análise e discussão das informações}

Com base nas idéias apresentadas, pode-se afirmar que a aquisição do conhecimento implica uma estreita relação entre sujeito-objeto e isso se estabelece através da ação como meio para construir novas estruturas, conceitos e aquisição de novas culturas no espaço universitário. Essa ação pode ser amplamente refletida no cotidiano universitário, levando os acadêmicos a repensarem posturas, levantarem hipóteses, interpretar, criar e se relacionar com diferentes culturas existentes no ambiente universitário. No caso dos estudos dirigidos para o multiculturalismo há uma 
intencionalidade, pois eles buscam alcançar um objetivo, coordena informações e emitem pontos de vista o que não é muito diferente nos demais processos educativos.

O estudo dirigido como qualquer outra ação pedagógica sugere uma seqüência lógica e pode estar vinculado a metodologias diversas; segui-las é uma de suas etapas. $\mathrm{Na}$ realidade toda atividade que envolve método implica compreender instruções verbais ou não verbais para se chegar a um objetivo. No caso específico do estudo dirigido, interagir favorece a aprendizagem, pois nessa dinâmica o acadêmico aprende a conhecer a si mesmo, a maneira como pensa e atua. Numa atividade dialogada aprende diferentes visões de mundo e da sociedade, especialmente quando desenvolvida em equipe, a qual aprimora as suas relações sociais à medida que desenvolve suas competências aceitar diferentes pontos de vista e opiniões.

Todo estudo dirigido intercultural há de enfocar um contexto para que os conteúdos sejam trabalhados de modo a colaborar na apreensão dos assuntos enfocados em sala de aula (FLEURI, 2003). Nesse sentido, toda forma de diálogo pode ser utilizada quando a finalidade é promover a aquisição de conhecimento e estimular aprendizagens significativas. A ação de dialogar corresponde, portanto, a um conjunto de ações intencionais e integradas a um todo harmônico e desafiador. Dessa maneira o profissional da educação deve estar bem seguro das culturas que se pretende refletir.

É imprescindível em uma atividade revestida de teor intercultural estabeleça uma relação positiva para que educandos com visões preconceituosas e destorcidas possam modificar sua imagem negativa em relação à diversidade cultural existente em nosso país. Nesse sentido a interação pode demonstrar que aprender é uma dinâmica interessante e facilita a aquisição da autoconfiança e autonomia. Sendo assim, o educador deve incentivar o estudante a questionar e corrigir suas ações quando necessário, analisar e comparar diferentes pontos de vista e organizar os materiais utilizados (MARQUES, 2003).

No desenrolar de um diálogo, criam-se situações que permitem ao universitário desenvolver seu raciocínio através do agir e do pensar, adotando critérios a fim de se obter um bom relacionamento social. Dessa maneira, busca-se enfatizar os processos necessários ao ato de aprender contribuindo para a formação do futuro profissional. É imprescindível que os universitários busquem, através da iniciativa própria, uma 
maneira prazerosa e sensata de organizar suas próprias idéias e opiniões. Uma atitude dialógica pode estimular a curiosidade do outro e motivá-lo a empreender um espírito de investigação bem como a busca de soluções criativas.

No contexto dos estudos dirigidos, os profissionais da educação podem identificar e localizar as principais deficiências para orientar o acadêmico a compreender culturas até então desconhecidas. Auxiliar o estudante universitário a eliminar as barreiras culturais e caminhar rumo a novas aprendizagens é essencial para que seja produtor de suas ações. Quando isso acontece, constroem-se habilidades com as quais irão trabalhar as diferentes situações de seu cotidiano. Competências como observar, indagar, ponderar, interpretar, solucionar e analisar são passíveis de ser adquiridas no contexto dos estudos dirigidos e durante uma dinâmica prazerosa. Quando o acadêmico expressa sua cultura é capaz de aprender a persistir e melhorar seu desempenho na medida em que emerge uma vontade própria de superar suas limitações e preconceitos.

Quando se dialoga interculturalmente e discute diferentes abordagens, muitos conceitos, atitudes, comportamentos e reações são reavaliados, bem como diferentes aprendizagens são ampliadas, reformuladas ou aprofundadas (FLEURI, 2003). Essa avaliação indica caminhos para aprimorar o nível de compreensão do acadêmico e ao mesmo tempo serve como referência para o educador orientar as multiculturas com mais disposição e confiança.

Uma dinâmica que envolve estudo dirigido dialogado deve ter como parâmetro o respeito às diferenças individuais dos integrantes observando e reforçando mudanças de opiniões rumo à erradicação do preconceito (ROMÃO, 2005). Nesse contexto, pode-se ainda identificar e valorizar todos os progressos científicos levando-a a analisá-los de modo a incentivar o universitário a buscar outras competências e desenvolver talentos ainda não explorados. Deve-se, no entanto, mostrar aos alunos as semelhanças que existem entre o ato de dialogar e as atividades profissionais futuras.

Vale dizer ainda que o diálogo intercultural enriquece o processo de aprendizagem no qual o sujeito é levado a refletir de modo a atuar adotando postura crítica, autonomia e criatividade. Outra característica de um estudo dirigido dialogado é proporcionar, ao profissional em formação, condições para fazer previsões e inter- 
relacionar objetos, pessoas e eventos. Isso porque, para o educador, o estudo dirigido contribui no fornecimento de informações a respeito de quem está interagindo e auxilia a compreensão do pensamento acadêmico.

É possível, no contexto dos estudos dirigidos, criar condições para que a equipe como um todo possa descobrir e tomar ciência que aprender é possível, sem grandes esforços e com prazer. Mesmo as atividades mais formais encaradas no contexto universitário podem ser feitas com prazer, despertar o interesse pela leitura, pelo tema proposto, aprimorar habilidades e prender a atenção dos acadêmicos.

\section{Considerações Finais}

Ao finalizar este relato, pudemos levantar as valiosas contribuições que a equipe pedagógica possa fazer ao lidar com diversidade em diferentes espaços acadêmicos, ao eliminar, gradativamente, os focos de discriminação de qualquer natureza. Pelas informações analisadas, pudemos observar que, aliados aos universitários, os professores podem lançar diferentes olhares, buscando idéias na educação intercultural.

Quando se estuda a diversidade cultural, étnica, social em um contexto - no nosso caso o universitário - à luz de idéias inovadoras e de vanguarda, percebemos a necessidade de valorizar o ser humano, sua bagagem cultural e sua história de vida. Nessa perspectiva, é necessário elaborar e planejar estratégias para instruir um estudo dirigido que facilite o diálogo multicultural.

Uma das contribuições mais importantes dessas reflexões é que devemos auxiliar o acadêmico a descobrir e buscar as suas próprias maneiras e idéias ao lidar com as diferenças culturais dentro e fora da instituição de educação superior, porque fora do contexto cultural irá ligar com diferentes culturas. Devemos elaborar juntos uma proposta pedagógica capaz de levar o universitário a despertar sua consciência crítica e sua curiosidade científica em relação aos fatos sociais que originam as diferenças culturais, sociais, políticas, étnicas, entre outras. À medida que compreende suas próprias diferenças, o indivíduo é capaz de escolher caminhos a trilhar com a finalidade de obter sucesso em sua formação profissional. 


\section{Referências}

AMARAL, Ana L. Aula Universitária: um espaço com possibilidades interdisciplinares. In: VEIGA, I. P. A. e CASTANHO, M. E. L. M. Pedagogia Universitária: aula em foco. Campinas: Papirus, 2000, p. 258.

BRASIL, Ministério da Educação e do Desporto. Parâmetros Curriculares Nacionais, 1996.

BALZAN, N. C. Indissocialidade ensino-pesquisa como princípio metodológico. In: VEIGA, I. P. A. e CASTANHO, M. E. L. M. Pedagogia Universitária: aula em foco. Campinas: Papirus, 2000, p. 258.

CASTANHO, M. E. L. M. A criatividade na sala de aula universitária. In: VEIGA, I. P. A. e CASTANHO, M. E. L. M. Pedagogia Universitária: aula em foco. Campinas: Papirus, 2000, p. 258.

CANDAU, Vera Maria. Interculturalidade e educação escolar. ENCONTRO NACIONAL DE DIDÁTICA E PRÁTICA DE ENSINO. Águas de Lindóia, 1998.

CUNHA, M. D. e SOUZA JUNIOR, A. J. O processo de ensino-aprendizagem no cotidiano de uma escola plural. In: FONSECA, S. G. (org.). O uno e o diverso na educação escolar. Uberlândia: EDUFU, 2005, p. 125.

DAYRELL, J. A escola como espaço sócio-cultural; in: Dayrell, J._Múltiplos Olhares sobre educação e cultura. Belo Horizonte: UFMG,1996, p. 266.

FLEURI, R. M. Educação Intercultural: mediações necessárias. São Paulo: DP\&A, 2003, p. 198.

FONSECA, V. M.; AMARAL, R.L. Ação Docente e a Diversidade Humana. Londrina: Unopar, 2005, p. 25.

LIMA, M. L. R. A aula universitária: uma vivência de múltiplos olhares sobre o conhecimento em situações interativas de ensino e pesquisa. In: VEIGA, I. P. A. e CASTANHO, M. E. L. M. Pedagogia Universitária: aula em foco. Campinas: Papirus, 2000 , p. 258.

LOPES, R. M. G. P. Concepções pedagógicas e emancipação humana: um estudo crítico. In: PIMENTA, S. G. (org.). Saberes pedagógicos e atividade docente. 4.ed. São Paulo: Cortez, 2005, p. 323.

MARQUES, M. O. Formação do profissional da educação. ljuí: Unijuí, 2003.

MOREIRA, A. F e SILVA, T. T. da. Currículo, cultura e sociedade. 2. ed. São Paulo: Cortez, 1997.

PIMENTA, S. G. Formação de professores: identidade e saberes da docência. In: PIMENTA, S. G. (org.). Saberes Pedagógicos e Atividade Docente. 4.ed. São Paulo: Cortez, 2005, p.323. 
ROMÃO, J. E. Avaliação dialógica: desafios e perspectivas. São Paulo: Cortez, 2005, p. 189.

Recebido para publicação em: 24/11/2008

Aceito: 20/12/2008 